\title{
Analysis of Core Technology Problems and Countermeasures in the Robot Industry
}

\begin{abstract}
Xiguang Zhang*
Beijing Laboratory of National Economic Security Early-warning Engineering, Beijing Jiaotong University, Beijing 100044, China

*Corresponding author: Xiguang Zhang, tete717@outlook.kr

Abstract: Since 2013, China has been the world's largest market for industrial robots. Despite the gradual maturity of the industrial robot system, the lagging R\&D and backward technology level of industrial robots have led to a strong dependence on the import of core components and key technologies, which to a certain extent has restricted the development and improvement of industrial robots. At present, the "neck problem" in the field of industrial robots in China is not only in the reducer, controller, and servo but also in the basic processing equipment, basic technology, and basic materials. In this paper, we propose measures to improve the "neck problem" of industrial robots to promote the high-quality development of industrial robots in China.
\end{abstract}

Keywords: Industrial robots; "Neck problem"; Core components; Key technologies; Infrastructure equipment

Publication date: November 2021; Online publication: November 30, 2021

\section{Introduction}

At present, industrial robots play an indispensable role in the manufacturing industry, significantly improving product production efficiency and quality. Along with the rapid development of the world economy, the manufacturing industry is becoming increasingly competitive, and the development and popularization of industrial robots not only improves the efficiency of the manufacturing industry but also enhances the advantages of China's manufacturing industry in the international competition system and can accelerate the transformation and upgrading of China's industry.

Although China's industrial robots ranked first globally in terms of cumulative installed capacity in 2019, the "neck problem" still exists in core components and key technologies. In this paper, through a systematic review and analysis of the "neck problem" of China's industrial robots and the subdivision of China's industrial robot manufacturing process, we conclude that the crux of the "neck problem" is not all the three major components in general, but also exists in It is also found in the essential equipment, process, materials, and other aspects. This paper provides theoretical, practical, and policy references to accelerate the solution of the "neck problem" of industrial robots in China by strengthening basic research, disruptive innovation, setting up special R\&D funds, strengthening collaboration between industry, academia, and research institutes, and introducing and cultivating top scientific and technological talents and artisanal talents.

\section{History of China industrial robot development}

The development of industrial robots in China has gone through four stages: in the first stage (1970s to early 1980s), the basic theory of industrial robots was studied, and some progress was made in robot kinematics and mechanics, which laid the foundation for future industrial robot research ${ }^{[1]}$; In the second 
stage (mid-1980s), the government attached importance to and supported the development of industrial robots. The state organized surveys on industries requiring industrial robots and invested a lot of money in the research of industrial robots ${ }^{[2]}$; In the third stage (1990s), seven kinds of industrial robots were developed, and more than 100 robot application projects were implemented, which promoted the industrialization of domestic robots; In the fourth stage (21st century), the government actively created a policy environment conducive to independent innovation, accelerated the promotion of enterprises to become the main body of innovation, and vigorously advocated enterprise-oriented, industry-oriented, and industrial robots ${ }^{[3]}$.

With the advancement of robotics to meet the increasing demand of automated production, robots dominate the third industrial revolution, in which a new generation of robots with intelligence as the core, high-speed networks, and cloud storage robots become the terminals and nodes of the Internet of Things ${ }^{[4]}$. The world's developed countries have elevated robotics development to the height of national strategy, and many countries have taken robotics as an important entry point to enhance competitiveness. British economist Paul McGillivray believes that the third industrial revolution based on the Internet, materials, and energy, with "digital intelligent manufacturing" as the core, is coming, and the main body of "intelligent digital manufacturing" is industrial robots ${ }^{[5]}$. As important basic equipment for a country's industrial development, industrial robots are an essential symbol of a country's scientific and technological innovation and manufacturing level, which can promote industrial transformation and upgrading and is also an important entry point to accelerate the construction of a strong country.

\section{China's industrial robots and core components development status}

\subsection{The current situation of industrial robots}

Marked by the high-speed promotion of industrial Internet development, China's robotics development has been remarkable under the continuous support and promotion of national policies, enterprises, funds, and other production factors. 2013 became the world's largest industrial robot market, with about 140,500 new industrial robots installed in 2019. According to the China Electronics Association, the global robotics market size reached $\$ 29.41$ billion in 2019 ; China is about $\$ 8.68$ billion, of which $\$ 5.73$ billion for industrial robots, accounting for about $66 \%$ of the robotics market share. In addition, according to the National Bureau of Statistics data, the annual production of industrial robots in China has gradually increased since 2002, and the production in 2019 was 186,943 sets, an increase of 26.6\% compared with 2018, accounting for $50.1 \%$ of the total global production. The average density of industrial robots worldwide in 2019 was 114 sets/million people, and the installed density of industrial robots in China was $187 \mathrm{sets} / \mathrm{million}$ people. The global ranking is 15 th, which is higher than the world average, but there is still a gap compared with developed robotics countries, which shows that there is still a large upside in China's robot density.

\subsection{The status of core components}

In industrial robot $R \& D$ technology, reducers, servers, and controllers are the three most challenging core components and the most profitable segments, accounting for 36\%, 24\%, and $12 \%$ of the total cost of industrial robots, respectively. Core components and critical technologies determine essential performance indicators of robots, such as accuracy, load capacity, stability, and reliability. Having core components and key technologies can occupy the high ground in the field of industrial robots.

(1) In terms of reducer, due to the late start of China's industrial robots, infrastructure, technology level backward and other reasons, resulting in most of the domestic industrial robots using reducers dominated by foreign enterprises. Along with the development of China's industrial robots, from the product classification, the domestic harmonic reducer progresses relatively fast, at present, Suzhou Green Harmonic Transmission Technology Co. The development of R.V. reducer is 
relatively slow, and there are relatively few manufacturers who can mass-produce, and it is a little weak in market share and brand degree.

(2) Servo, with the progress of science and technology, A.C. servo system technology is becoming more and more mature, the cost continues to decline, A.C. servo motor gradually replaced D.C. servo motor to become the mainstream of mechatronics technology production system motor, in industrial robots, CNC machine tools, and other fields, the application of A.C. servo system is becoming more and more widespread ${ }^{[6]}$. Although China's servo system in the quality and technical level is progressing, compared with internationally renowned enterprises, the overall performance and reliability there are more problems, foreign enterprises about $80 \%$ occupy the domestic highend server market.

(3) controller, although the controller in the core components accounted for a relatively low but plays a vital role in robot control. The process of control system development, it involves many core technologies such as hardware design, underlying software technology, and upper layer function application software. Through years of precipitation and technology accumulation, the gap between domestic brands and foreign brands in the controller hardware platform is gradually narrowing. However, due to the lack of platform foundation, most of the controllers produced by domestic manufacturers use a closed structure, its poor openness, poor software independence, fault tolerance, poor scalability, lack of network functions, it is difficult to adapt to the requirements of intelligence, flexibility ${ }^{[7]}$.

\section{The key technology is the "neck problem"}

\section{1. (R.V.) reducer domestic technology is weak, and the import volume is large}

At present, about $75 \%$ of the world's precision reducers are monopolized by two Japanese companies, Nabtesco and Harmonic Drive, of which, Nabtesco's R.V. reducer accounts for about $60 \%$ of the market share and Harmonic Drive accounts for $15 \%$ of the market share. R.V. reducer is a two-stage closed transmission mechanism based on the cycloidal planetary reducer. Closed transmission mechanism, due to its small size, strong impact resistance, high torque, high positioning accuracy, slight vibration, large reduction ratio, widely used in industrial robots, machine tools, medical testing equipment, satellite receiving systems, and other fields, its fatigue strength, stiffness, life, and other performance are better than the general robot harmonic transmission, and the return accuracy is stable, many countries in the world high-precision robot transmission mostly use R.V. reducer. R.V. reducer has the trend of gradually replacing harmonic reducer in the advanced robot drive ${ }^{[8]}$. There are no outstanding enterprises in China's R.V. reducer enterprises, and the development of R.V. reducer is based on high technology and high investment as the primary threshold, which causes difficulties for R\&D enterprises to enter the market. The technical level of R.V. reducer in China has more precision, stability, speed, noise, life, etc., especially in the "neck problem" in the development system of industrial robots.

\subsection{The server and the leading international enterprises technology problem points}

The server is the engine that controls the operation of mechanical components in the servo system of industrial robots, a kind of variable speed device between subsidized motors. The server is generally installed in the robot's "joints", which is the heart of the robot movement. Domestic high-end servers are monopolized by foreign enterprises by nearly $80 \%$ market share, the Japanese servo products stable performance can meet the requirements of most applications, especially small power motors, the advantages are relatively obvious, the advantages of European products in high-speed and precision areas more obvious. Server manufacturing high-temperature-resistant materials, encoder technology, feedback components, magnetic materials, power modules mainly rely on imports, is the focus of the development of China's 
server "neck problem." Imported and domestic servers can be seen, domestic server signal plug-in, response speed, pulse frequency, resolution, work accuracy and other aspects of the leading international enterprises, and the gap are relatively obvious.

\subsection{The controller in the software level to be improved}

The controller is called the "brain" of the industrial robot, and its performance plays a crucial role. Its main task is to control the robot's motion position, attitude, and trajectory in the working space ${ }^{[9]}$. The industrial robot controller mainly includes hardware and software parts. As most of the hardware is outsourced, almost all industrial robot suppliers can purchase the same hardware. The main problem of domestic and foreign robot controllers is reflected in the software part, that is, the control algorithm and the ease of use of the secondary development platform ${ }^{[10]}$, which is the focus of the "neck problem" in the development of China's industrial robots in the controller. Domestic controllers are relatively lacking in operational stability, applicability, and precision due to the lack of software technology, causing the domestic controller market to be occupied by foreign countries with a larger market share. With the accumulation of domestic robot technology and application experience, domestic controller products are relatively mature and are the core components with the smallest technological gap with foreign countries.

In addition, in the basic processing equipment and materials, due to technical and technological problems, resulting in the production of parts in the stability, precision, reliability and other aspects of the severe shortage. For example, parts processing equipment in the machine tool equipment high-end technology is still monopolized by foreign countries, especially CNC machine tools supporting equipment $90 \%$ need to be imported, most of the key zero parts are controlled by Germany, Japan. China's high capacity in steel, aluminum, copper, and other metals, although it can replace the demand for some products, due to the demand for industrial robots' core parts quality, some companies still need to rely on imported materials. Basic processing equipment, technology, and materials are also important factors leading to the "neck problem" of industrial robots.

Industrial robots play an important role in China's economic development and can effectively optimize the economic structure and diversify, rationalize, and make China's economic industry more efficient, and the development of industrial robots is the top priority of China's development at this stage. The "neck problem" is reflected in the technical aspects, including basic equipment and basic materials. Due to the monopoly of technology by developed countries in China, the cost of industrial robots remains high, so that many enterprises in China cannot enjoy its value, which directly affects the development of enterprises and has a huge impact on China's economy, national security and industrial security.

\section{Suggestion}

\subsection{Set up a special R\&D fund for robotics to help solve the "neck problem" of key technologies}

Because of the late exploration of scientific research for robotics in China, the research and development capability are relatively weak, the technology is backward, the performance is poor, and the strength is disparate compared with the developed countries of Japan and Europe robotics. The ratio of basic research to $R \& D$ funding in developed countries is about $15 \%-25 \%$, while the ratio of basic research to $R \& D$ in China is only about $1 / 3$ to $1 / 5$ of theirs ${ }^{[11]}$. The core components and key technologies of robots require a high technical level and more difficulties, which are part of a long R\&D cycle, high investment, and high energy consumption, requiring a long time and high investment to effectively promote technological progress. China's scientific research is basically centered on universities and research institutes, and the investment in special R\&D can improve the research equipment and research environment and also stimulate the innovation vitality, efficiency, and enthusiasm of researchers to achieve more original results, thus enhancing innovation and creativity. The establishment of special core $R \& D$ can speed up the 
conversion rate of basic and applied research results and has a positive effect on the improvement of the "neck problem."

\subsection{Adopt disruptive innovation}

Disruptive innovation refers to replacing imports with domestic production, cutting into the "neck" problem point, improving product quality and service level, subverting the existing market pattern, destroying the domestic monopoly, breaking through the existing business model, increasing the localization rate and achieving a bend in the road. The essence of disruptive innovation is technological innovation, which can promote product innovation and corporate breakthroughs, bring new business models and open up new markets. Disruptive innovation requires precise positioning and analysis of the market, grasping the internal and external market environment, and strengthening basic research in order to effectively implement disruptive innovation strategies.

\subsection{Enterprise-based, to strengthen the collaborative innovation of industry, academia, and research} Science and technology innovation is an important driving force for economic and social development, and it is important to build an industry-university-research collaborative innovation system with enterprises as the main body. At present, China's science and technology power is mainly distributed in scientific research institutions and universities, and enterprises' science and technology R\&D power is relatively weak, with little R\&D investment, few R\&D institutions and weak innovation ability. Enterprises should take the national support as an opportunity to actively cultivate the awareness of scientific and technological research, strengthen the collaborative innovation of industry-university-research, breakthroughs in basic equipment, basic processes, basic materials and other issues, and accelerate the rate of transformation of scientific and technological achievements.

\subsection{Strengthen the introduction and cultivation of talents and enhance the level of basic research}

The lack of professional talents is an important factor restricting the development of industrial robots in China. In terms of talent introduction and cultivation, we will vigorously implement the plan of introducing high-level innovative talents, actively introduce and cultivate innovative high-end talents and artisan talents, establish and improve a reasonable talent introduction and cultivation mechanism, enhance the basic research and innovation capability of China's industrial robots, and promote the further enhancement and development of core components and key technologies of China's industrial robots.

\section{Conclusions}

The demand for industrial robots is growing, and the market size of industrial robots is growing every year and is expected to have higher growth space in the future. To break through the status quo of core field constraints, we also need our own continuous efforts and innovation to turn problem points into motivation, focus on breaking through core field problems, and make the core field of industrial robots into a completely independent and controllable production mode, so as to break the bottleneck of industrial robot use.

\section{Acknowledgement}

This research is supported by Beijing Laboratory of National Economic Security Early-warning Engineering.

\section{Disclosure statement}

The author declares no conflict of interest. 


\section{References}

[1] Sun F, Sun Q, 2019, Investigation and Analysis of the Development Status of Industrial Robots in my Country. Mechanical transmission, (06): 172-176.

[2] Wang G, 2019, Industrial Robots Redefine the Factory. Internet economy, (Z1): 26-31.

[3] Zhao J, 2012, The Development Status and Challenges of Industrial Robots in my Country. Aviation Manufacturing Technology, (12): 26-29.

[4] Sun B, 2018, The Era of Robot Economy-Replacement with Machines Endowed with IQ and EQ. Frontier Economy and Culture, (02): 3.

[5] Our Editorial Department, 2018, Industrial Robots have Huge Development Space. Finance and Economic, (13):.46-47.

[6] Chen Y, Huang C. 2017, Comprehensive Experiment Development and Design of PLC Control of AC Servo Motor. Experimental Technology Management, (02): 147-150.

[7] Si W, 2019, The Expansion of Emerging Fields and High Cost Performance will Accelerate the Domestic Replacement of Industrial Robot Controllers. Guangzheng Hang Seng.

[8] He D, Li X, Li X, 2000, The Optimized New Tooth of the Cycloid of High Precision RV Reducer for Robot. Journal of Mechanical Engineering, 36(3): 51-55.

[9] Mi J, 2013, Industrial Robots: Mechatronics and IT Fusion. http://www.cena.com.cn/ai/20130329/40452.html

[10] Xu H, 2015, Industrial Robots: Here Break through Intelligent Modules. http://www.cena.com.cn/semi/20150901/69425.html

[11] Shen H, 2018, The Problem of Stuck Neck in the Field of Science and Technology needs to be Solved Urgently Core Technologies: Want to track but be original. Economic Daily. http://www.ce.cn/xwzx/kj/201806/12/t20180612_29408347.shtml 